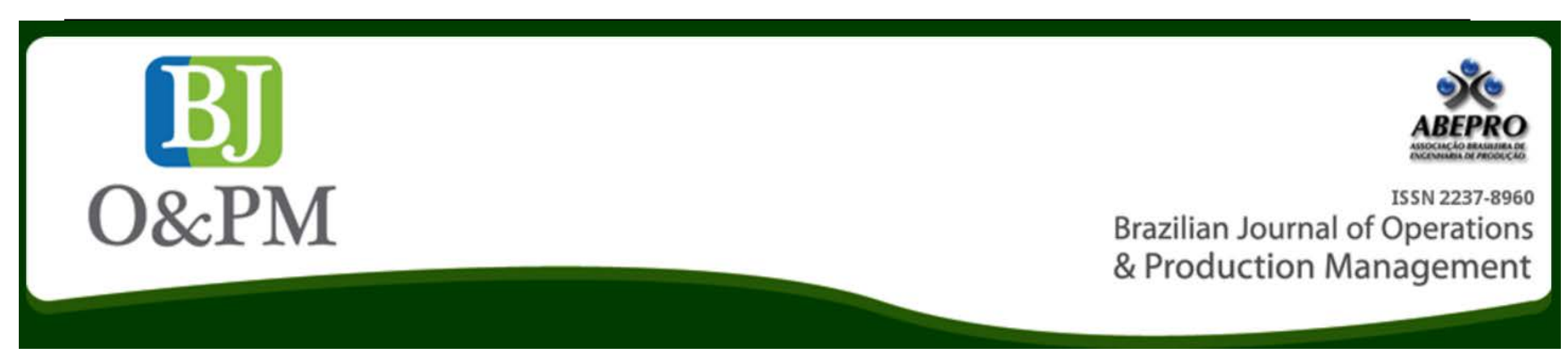

\title{
A BOW-TIE BASED RISK FRAMEWORK INTEGRATED WITH A BAYESIAN BELIEF NETWORK APPLIED TO THE PROBABILISTIC RISK ANALYSIS
}

\author{
Jose Cristiano Pereira ; Gilson Brito Alves Lima; Annibal Parracho Santanna ${ }^{a}$ \\ ${ }^{\text {a }}$ Fluminense Federal University (UFF) - Niterói, RJ, Brazil
}

\begin{abstract}
The use of probabilistic risk analysis in the jet engines manufacturing process is essential to prevent failure. It has been observed in the literature about risk management that the standard risk assessment is normally inadequate to address the risks in this process. To remedy this problem, the methodology presented in this paper covers the construction of a probabilistic risk analysis model, based on Bayesian Belief Network coupled to a bow-tie diagram. It considers the effects of human, software and calibration reliability to identify critical risk factors in this process. The application of this methodology to a particular jet engine manufacturing process is presented to demonstrate the viability of the proposed approach.
\end{abstract}

Keywords: Risk Analysis, Bowtie, Bayesian Network, Jet engine failure.

\section{INTRODUCTION}

Despite the impressive level of safety of today's aviation system, the accident rate has to be decreased still further. The main reason for that is the projected growth in air traffic movements (Aleet al., 2006). If the accident rate does not decrease, the growth of air traffic will inevitably lead to an increase in the absolute number of accidents regarded by many as unacceptable (Ale et al., 2006). This justifies the search for ways to actively pursue an increase in the jet engines manufacturing safety level by introducing integrated risk assessments and probabilistic risk analysis as an integral part of the manufacturing process.

The traditional method of assessing the system correctness relies on testing and simulation techniques. In simulation, the aim is to capture the system behavior and verify the correctness of the system by simulating different scenarios one by one using a model (Lahtinen et al., 2012). In order to be effective, a risk model should properly represent the interaction among human operator, software, hardware and environment and be able to capture the dependencies between system components. Safety Supervision, Safetyoriented Working Environment and system of Incentives and Penalties should be considered implementation priorities

ABEPRO

DOI: 10.14488/BJOPM.2015.v12.n2.a14 to improve overall performance in an organizational safety culture (Fu et Chan, 2013). Decision making should consider safety and operational risks. One of the most critical issues that every decision maker needs to face is the risk in association with the decisions to be finalized and the actions to be taken. (Lee et al., 2010).

The management of risks integrated with the operations of manufacturing is a huge challenge. However, it reduces accidents (Petersen, 2000) and improves productivity and the economic and financial performance of the company (Rechenthin, 2004). Systemic defects have become the major cause of most aviation accidents. While there has been a dramatic increase in the reliability of machines and computers over the years, the reliability of safety systems has not improved at the same pace. (Liou et al., 2008). The root cause of many disasters originates in maintenance workshops and in the factories, where vital components and systems have been produced (Janic, 2000). The bow-tie technique is suitable to build a model to be used as a tool in management decisions. It is important that the managers and their support teams be familiar with the value and application of these methods. The knowledge of experts in the process of jet engines manufacturing can be used to estimate the probability of engine failure. The information obtained from these experts should be combined in a formal way. Recent articles on human reliability claim that formal 
procedures are increasingly applied to elicit the opinion of specialists, especially when the quality and transparency of results are important. The goal of these formal methods is to achieve consensus in the ratings as a result. If the data are obtained systematically from well-informed experts in primary and secondary processes, the opinion of experts can offer acceptable precision in quantification.

Modeling is important to support midterm planning and decision making. The main strength of the modeling for companies lies in its ability to support decision processes in an iterative way (Nieuwenhuyse et Mahihenni, 2014). In the analysis process, the common problems faced are the lacking of required information and the accuracy of the information. Thus, it is necessary to have a systematic procedure to record the information for analysis. Still, the developed information collection system should be user friendly so that it is applicable in practical (Ding, Kamaruddin et Azid, 2014).

Considering the context presented above, this paper aims to present a proposal for probabilistic risk analysis based on bow-tie methodology combined with Bayesian Belief Network to analyze critical activities that can affect the reliability of the safety system in the manufacturing of jet engines. The research was focused on two main points. The first was the definition of the methodology to build a model based on fault tree, event tree, bowtie chart and Bayesian Belief Network. The second was the application of the model on a jet engines manufacturing process. The structure of the paper is divided into 5 chapters. The first section is the introduction highlighting the importance of probabilistic risk analysis in the jet engines manufacturing process. The second section presents the context and a brief description of techniques fault tree, event tree, bowtie chart and Bayesian Belief Network. The third section presents the methodology, the phases and the steps followed to build the model. The fourth section describes the application of the model to the jet engine manufacturing process. The fifth section presents the discussion of the results and the sixth and last sections presents the conclusion of the research.

\section{BACKGROUND AND CONTEXT}

Causal modeling using a bow-tie chart is a powerful tool for getting insight into the interdependencies between the constituent parts of complex system such as the manufacturing of jet engines. As far as safety is concerned, the propagation of fault situations in the engine manufacturing process can be modeled and followed. Weaknesses in protection against fault propagation can be systematically determined. The power of causal modeling can be greatly enhanced if probabilities and logical dependencies can be quantified (Nureg, 2001). Quantification has limitations mainly related to complexity of model and scarcity of data
(Pasman, 2013). These limitations may be overcome by expert's elicitation of probabilities.

By using causal models, the effect of safety measures or, conversely, the breach of safety barriers, can be quantitatively evaluated allowing comparisons between alternatives and cost benefit considerations. Many accident models have been suggested in the scientific literature; the underlying concept is the same: accidents result from a combination of factors, such as design errors, mechanical failures, software errors, user errors and organizational or regulatory factors (Marais et al., 2012; Ale et al., 2006). Causal models establish the theoretical framework of causes that might lead to engine failure and aircraft accidents. Causal models of assessment of risk and safety of aircraft operations establish the theoretical framework of causes that might lead to aircraft accidents (Netjasov et Janic, 2008). Methodologies for measuring complexity will assist designers in analyzing and mitigating the risks associated with product variety and its impact on manufacturing (Kamrani et al., 2011).

By estimating the probability of occurrence of each cause it is possible to predict the risk of accident. This can be restricted to pure statistical analysis based on available data or it can combine such data with expert judgments of causes (Nureg, 2001). The framework of a causal model can combine Fault Tree Analysis - FTA, Event Tree Analysis - ETA, bow-tie Analysis and Bayesian Networks - BBN to estimate the probability of occurrence of each cause and thus predict the risk of failure of an engine. Based on causal scenarios derived from hazardous events, use of safety goals and risk uncertainty calculations are essential (Kumamoto, 2012). Pereira and Lima (2012a, c, d) describe some factors to be considered in the analysis. Table 1 presents the result of an in depth research about the techniques normally used for causal modeling. The latest papers (A), books (B), regulations and standards $(\mathrm{N})$ about the subject make reference to the use of fault trees, event trees, "bow-tie", human reliability analysis and Bayesian Networks for causal modeling.

\begin{tabular}{|c|c|}
\hline Method & Reference \\
\hline $\begin{array}{l}\text { Fault Tree } \\
\text { Analysis } \\
\text { (FTA) }\end{array}$ & $\begin{array}{l}\text { (B) Marszal et al. (2002), (B) Zio (2007), (B) } \\
\text { Kumamoto (2007), (T) Roelen (2008), (A) Netjasov, } \\
\text { Janic (2008). (B) Stolzer et al. (2010) (R) EASA-EASP } \\
\text { (2011),(B) Dias et al.(2011), (A) Mohanta (2011), (N) } \\
\text { NASA/SP-3421 (2011) (B) Fenton et al (2012), (N) } \\
\text { SAE JA } 1003 \text { (2012). }\end{array}$ \\
\hline $\begin{array}{l}\text { Event Tree } \\
\text { Analysis } \\
\text { (ETA) }\end{array}$ & $\begin{array}{l}\text { (B) Marszal at al. (2002), (B) Zio (2007), (B) } \\
\text { Kumamoto (2007), (A) Netjasov, Janic (2008), (T) } \\
\text { Roelen (2008), (B) Stolzer et al. (2010), (R) EASA- } \\
\text { EASP (2011), (B) Dias et al.(2011), (B) Rausand } \\
\text { (2011), (N) NASA/SP-3421 (2011), (B) Fenton et al } \\
\text { (2012), (N) SAE JA } 1003 \text { (2012). }\end{array}$ \\
\hline
\end{tabular}




\begin{tabular}{|c|c|}
\hline Bowtie & $\begin{array}{l}\text { (A) Zuijderduijn (2000), (A)Trbojevic and Carr (2000), } \\
\text { (B) Kumamoto (2007), (A) Netjasov, Janic (2008), (T) } \\
\text { Roelen (2008), (R) EASA-EASP (2011), (B) Rausand } \\
\text { (2011), (T) Espen (2011), (N) NASA/SP-3421 (2011), } \\
\text { (B) Dias et al.(2011), (B) Fenton et al (2012), (N) SAE } \\
\text { JA } 1003 \text { (2012), (A) Pasman (2013). }\end{array}$ \\
\hline $\begin{array}{l}\text { Bayesian } \\
\text { Belief } \\
\text { Networks } \\
\text { (BBN). }\end{array}$ & $\begin{array}{l}\text { (A) LuxHoj (2002), (A) Stamelos (2003), (A) } \\
\text { Droguett et al. (2007), (A) Netjasov, Janic (2008), (R) } \\
\text { EASA-EASP (2011), (B) Rausand (2011), (B) Dias et } \\
\text { al.(2011),, (A) Brooker (2011), Yorukoglu (2011), (A) } \\
\text { Nott et al. (2011), (A) Mohanta (2011), ((B) Fenton } \\
\text { et al (2012), A) Axu (2012), (A) Podofillini (2013), } \\
\begin{array}{ll}\text { (A) (Groth e al. (2013), (A) Konovessis et al.(2013), } \\
\text { (A) Pasman (2013). }\end{array}\end{array}$ \\
\hline FMEA & $\begin{array}{l}\text { (B) Zio (2007), (B) Kumamoto (2007, (B) Stolzer et al. } \\
\text { (2010) (R) EASA-EASP (2011), (B) Dias et al.(2011), } \\
\text { (A) Cambacedes (2013). }\end{array}$ \\
\hline
\end{tabular}

Table 1 - Publications referencing techniques for causal modeling

Table 1 shows that the modeling techniques most referenced by authors in state of the art literature about probabilistic risk analysis are fault tree, event tree, bow tie and Bayesian networks. The following items describe these techniques in detail.

\subsection{Bow-tie Modeling}

Trbojevic et Carr (2000) state that in the most known uses of the bow-tie technique, it is utilized as part of assessments undertaken with a view to reduce accidents based on equipment failure. According to Zuijderduijn (2000) the management of hazards and their effects, through the application of a process called Hazard And Effect Management Process, which at its core produces bow-tie diagrams, describes the various hazards that can occur and the existing process and equipment controls to prevent these from occurring, or reducing the impact were these hazards to cause a loss event. Bow-tie analysis can be used for both qualitative and quantitative risk assessments in complex situations. A bow-tie chart is used to show the combination of a fault tree on the left and an event tree on the right. Fig. 1 shows the fault tree connected via the top event named TE to the event tree.

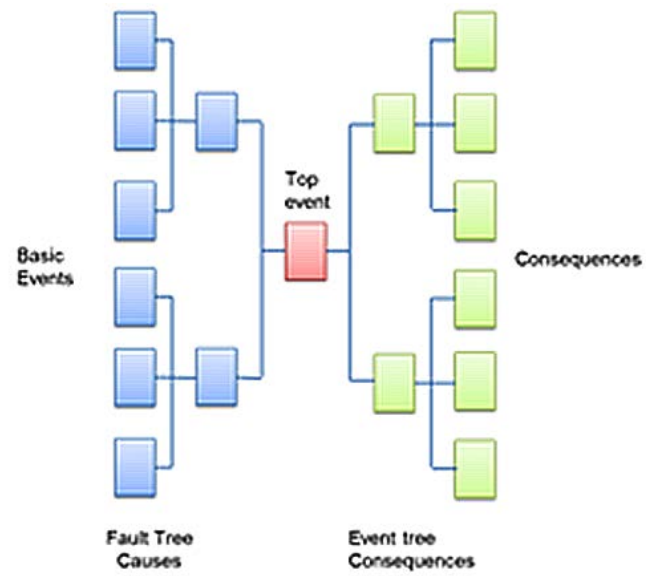

Pereira et al., (2014e, f, g) addressed the bow-tie diagram shown in Figure 1, the left side of a bow-tie diagram resembles a Fault Tree. The fault tree method was created in 1962 and quickly became popular in the nuclear and aviation industry. A fault tree uses Boolean AND/OR gates to model causal relationships between events (the method is mostly used to model the causality of unwanted events, but it is possible to model any kind of causal relationship). In order to quantify the event tree, the probabilities of occurrence of the initial event and the success or failure of the reactive layers are considered. Considering that the fault trees are used to obtain the probability of a system failure, the fault tree may be combined with the event tree to form a bow-tie diagram. The pivot event is the final failure event obtained with the fault tree and the initial event for the event tree. The pivot event may occur or not, which leads to different final situations. Each path through the diagram is a scenario. A bow-tie based model employs the combined fault tree and event tree and allows the representation of several scenarios.

The bow-tie method is most often used for the analysis of Major Hazard Scenarios in which the consequence spectrum is so bad that keeping control over these Hazards is of major importance, regardless of the actual probability of the consequences. Fortunately there is little accurate information available about the frequency of these worstcase-scenario consequences. Bow-tie models are tools for integrating broad classes of cause-consequence models. The familiar fault tree and event tree models are 'bow tied' in this way; indeed, attaching the fault tree's top event with the event tree's initiating event originally suggested the bow-tie terminology. However, any other cause and consequence models can be used as well (Ale et al., 2006).

\subsection{Bayesian Network Modelling}

Bayesian Networks, also called Bayesian Belief Networks (BBNs), have become an increasingly popular part of the 
risk and reliability analysis framework due to their ability to incorporate qualitative and quantitative information from different sources, to model interdependency, and to provide a causal structure that allows probability risk analysis practitioners to gain deeper insight into risk drivers and into specific interventions that reduce risk (Mosleh 1992; Rechenthin, 2004). A Bayesian network is a powerful tool for various analyses (E.g.: inference analysis, sensitivity analysis, evidence propagation, etc.) Sutrisnowati et al., 2014). There has been an increasing trend in the literature and in the application of Bayesian networks in fields related to reliability, safety and maintenance (Mahadevan et al., 2001; Weber et al. 2012). Bayesian approaches to aggregate expert judgments on probabilities have been extensively investigated in risk and reliability analysis (Podofillini, Dang, 2013, Mosleh, 1986; Droguett et al., 2004). BNs provide a framework for addressing many of the shortcomings of human reliability analysis from a researcher perspective and from a practitioner perspective (Groth, Swiler, 2013, Boring et al., 2010). External human performance factors depend on company, society and technology (Calixto et al., 2013). The human reliability analysis is a systematic framework, which evaluates the process of human performance and the associated impacts on structures, systems and components for a complex facility (Cepin, He, 2006, Cepin, 2007).

There are many varieties of Bayesian analysis. The fullest version of the Bayesian paradigm casts statistical problems in the framework of decision making. It entails formulating subjective prior probabilities to express pre-existing information, careful modelling of the data structure, checking and allowing for uncertainty in model assumptions, formulating a set of possible decisions and a utility function to express how the value of each alternative decision is affected by the unknown model parameters. Due to their ability to incorporate qualitative and quantitative information from different sources, Bayesian Networks (BNs), also called Bayesian Belief Networks (BBNs) have become an increasingly popular part of the risk and reliability analysis framework to model interdependency, and to provide a causal structure that allows probability risk analysis practitioners to gain deeper insight into risk drivers and into specific interventions that reduce risk (Mosleh, 1992; Rechenthin, 2004). Over the last decade, bibliographical reviews in the state of the art literature have focused on the use of Bayesian networks on dependability, risk analysis and maintenance. It shows an increasing trend of the literature to address the application of Bayesian networks in fields related to reliability, safety and maintenance (Mahadevan et al., 2001; Weber et al., 2012). The node represents random variables and arcs represent direct dependency between variables relations. The arcs direction represents cause effect relation between variables. Fig. 2 represents the Bayesian Network, being node $\mathrm{H}$ consequence from causes $T$ and $P$.

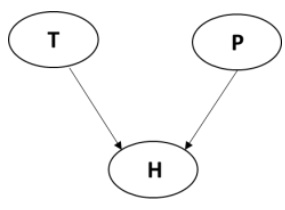

Fig.2. Bayesian network

In Figure 2, nodes $\mathrm{T}$ and $\mathrm{P}$ are fathers of $\mathrm{H}$ and are called ancestral of $\mathrm{H}$. In Human Reliability analysis, for example, the Nodes $\mathrm{T}$ and $\mathrm{P}$ represents performance human factors and node $\mathrm{H}$ represents human error probability conditioned to human performance factors $T$ and $P$. In each node there is a conditional probability table, which represents variables. General equation (1) represents the probability of occurrence of variable $\mathrm{H}$ conditioned to the occurrence of variables $\mathrm{T}$ and $\mathrm{P}$.

$H=\sum_{i=0}^{1} * \sum_{j=0}^{1} * p(H=1 / T=I, P=j) * p(T=i) * p(P=j)$

Equation (2) estimates the probability of variable $\mathrm{H}$ becoming true, conditioned to variables $\mathrm{P}$ and $\mathrm{T}$ being true or false.

$$
\begin{aligned}
\mathrm{P}(\mathrm{H}=\text { true })= & p(\mathrm{H}=\text { true } / \mathrm{T}=\text { true }, \mathrm{P}=\text { true })^{*} \mathrm{p}(\mathrm{T}=\text { true })^{*} \mathrm{p}(\mathrm{P}=\text { true })+ \\
& \mathrm{p}(\mathrm{H}=\text { true } / \mathrm{T}=\text { true }, \mathrm{P}=\text { false })^{*} \mathrm{p}(\mathrm{T}=\text { true })^{*} \mathrm{p}(\mathrm{P}=\text { false })+ \\
& \mathrm{p}(\mathrm{H}=\text { true } / \mathrm{T}=\text { false }, \mathrm{P}=\text { true })^{*} \mathrm{p}(\mathrm{T}=\text { false })^{*} \mathrm{p}(\mathrm{P}=\text { true })+ \\
& \mathrm{p}(\mathrm{H}=\text { true } / \mathrm{T}=\text { false }, \mathrm{P}=\text { false })^{*} \mathrm{p}(\mathrm{T}=\text { false })^{*} \mathrm{p}(\mathrm{P}=\text { false })+
\end{aligned}
$$

In human reliability, the Bayesian belief networks (BBN) methodology provides a greater flexibility as it not only allows for a more realistic representation of the dynamic nature of man and system, but also allows for the use of a methodology to represent a relationship of dependence among the events and performance shaping factors.

\section{INDUSTRY APPLICATION: PROBABILISTIC RISK ANALYSIS OF JET ENGINE FAILURE}

The operational system in jet engine manufacturing process needs to represent the causes of failure and their respective consequences. For this reason, a single representation of a scenario, with a cause-consequence diagram, is employed. This scenario considers the factors affecting human failure, software failure and calibration failure as related to engine failures. This cause-consequence method involves visualizing the possible alternative sequences composed by factors affecting human failure, software failure and calibration failure, and allows the undesirable event probabilities to be calculated from the factors affecting basic event probabilities. Application of a 
structured qualitative process risk analysis methodology, such as the Probabilistic Risk Analysis (PRA) allows quick identification and evaluation of the main risks of installations (Esteves et al., 2005). To identify the specific details, possible causes or contributing factors of risk events in the jet engines manufacturing process the entire process need to be mapped out and a qualitative risk analysis performed. Figure 3 shows the process map and the pivotal event, which is the incorrect assembly of an engine.

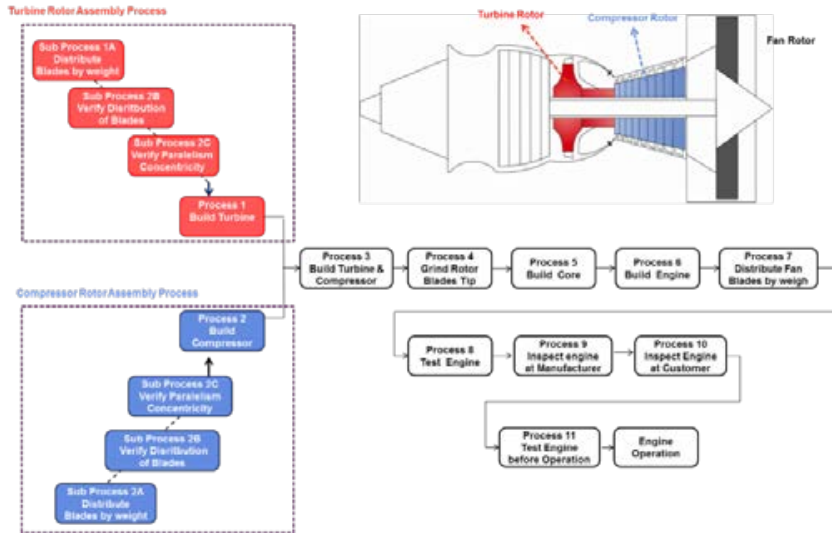

Fig.3. Combination of a fault tree and event tree

Process 6 shown in Figure 3 represents the pivotal element. The building blocks of the flowchart shown in Figure 3 represent the critical processes of the jet engine manufacturing system. In order to identify the critical steps and factors of risk in an operational situation, as well as to apply modeling methodologies suggested by the literature, specific sequences were followed. The proposed methodology utilizes fault tree, event tree and Bayesian networks combined in only one model and applied in an operational situation. Figure 4 shows the sequence of phases proposed to build the model.
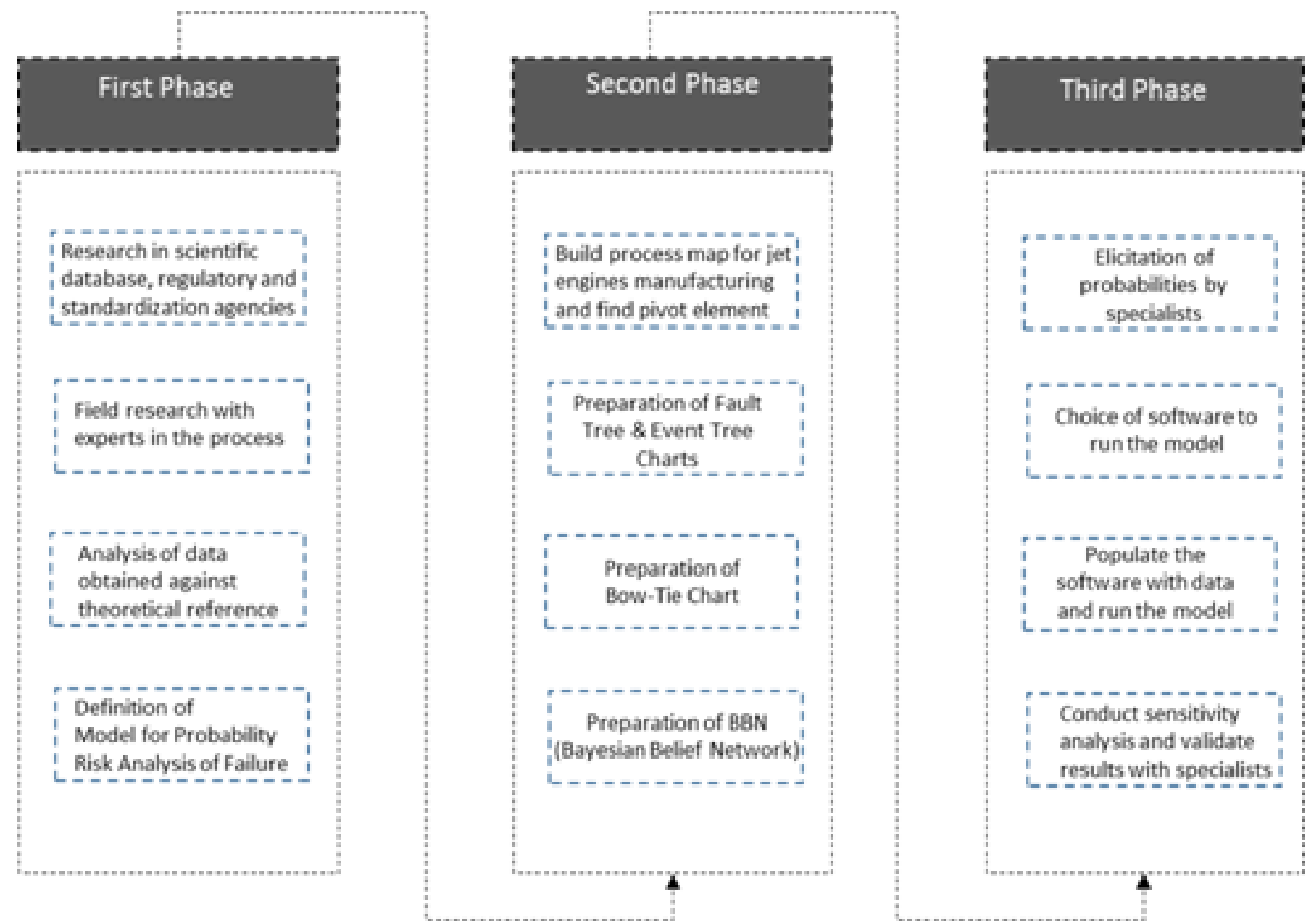

Fig.4. Phases and steps to develop the causal model 
In the first phase the causal model for application in the jet engine manufacturing process was conceived. To attain this objective, an in depth research was conducted, followed by a field research with experts in the process and then a detailed analysis of the data obtained against the applicable literature was performed in order to define the methodology to build the model to be used for the probability risk analysis. The result of this analysis is detailed in Pereira (2014b) an in Pereira . et al., (2014f, g). In the second phase the jet engine manufacturing process was mapped out and the pivot element was identified. The pivot event going in one of the directions, failure or non-failure was derived from the flow chart of the jet engine manufacturing process. In this specific model, the pivot event is the engine being manufactured with or without a defect. In the sequence, the fault tree was built with the sub-assembly processes and their respective preventive layers, then the event tree was built with the subprocesses and the reactive layers occurring after the pivot element. The fault tree and event tree are then combined to form the bow-tie chart. The last step in this phase is the preparation of Bayesian Belief Networks based on the primary risk factors and their interdependency. The bowtie chart and its application to jet engine manufacturing process are detailed in the paper entitled "Probabilistic Risk Analysis in Manufacturing Situational Operation" (Pereira, Lima, 2014g). In the third phase the probability of engine failure is estimated. The first step in this phase is to elicit the probabilities from experts, then populate the software with the elicited probabilities and adjust the model. The final step in this phase is to conduct sensitivity analysis to verify the accuracy and repeatability of the model. The result of the sensitivity analysis is being the object of a future paper in preparation.

\section{RESULTS AND DISCUSSION}

The fault-trees are constructed and quantified on the basis of the top event and expert opinion and a combination of different events causing the top event. These are connected by the logical gates and may have as many processes and preventive layers, as necessary, as shown in Figure 5.

Figure 5 represents different processes with their respective preventive layers. Each process may fail due to basic events related to failure of technicians in the execution process, software failure or calibration failure. These events are combined by the logical gate $O R$ and the occurrence of any of the events will cause the occurrence of the process failure.

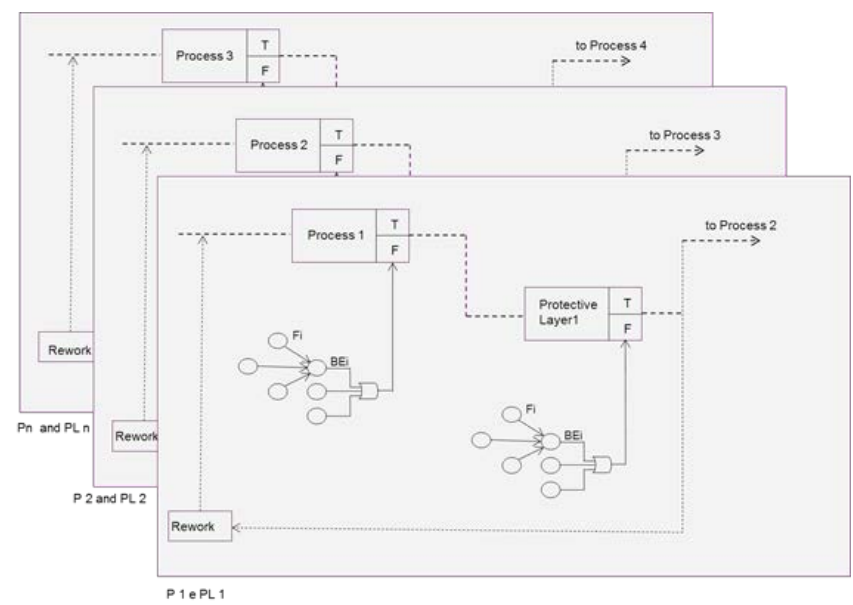

Fig.5. Processes and protective layers

Each protective layer may also fail due to the same basic causes related to failure of technician in the execution process, software failure or calibration failure. The basic events originating the failure of the processes and preventive layers may be triggered by several different factors that may have interdependency. Assuming independence, these factors are combined by using BBN. Equation (3) determines the probability of failure of intermediate event (Process 1 ):

$$
p(I E 1)=1-\prod_{i=}^{3}(1-q 1 i)
$$

Where:

$p($ IE1) $=$ probability of intermediate event (process 1$)$ failure

$q 1 i$ = probability of basic event failure (BEi) causing the failure of intermediate event 1 . The basic events could be failure of technician, failure of software or failure of calibration.

Equation (4) determines the probability of failure of the preventive layer 1 :

$$
p(P L 1)=1-\prod_{i=}^{3}(1-q 1 p i)
$$

Where:

$p(P L 1)=$ probability of failure of protective layer 1

$q 1 \mathrm{pi}$ = probability of basic event failure (BEi) causing the failure of protective layer 1 . The basic events could be failure of technician, failure of software or failure of calibration.

The probability of failure of process 1 and preventive layer 1 is determined by Eq. (5), which is the combination of (3) and (4). 


$$
p(I E 1 \text { and } P L 1)=\left[1-\prod_{i=}^{3}(1-q 1 i)\right] \quad\left[1-\prod_{i=}^{3}(1-q 1 p i)\right]
$$

Equation (6) determines the probability of failure of process $\mathrm{n}$ :

$$
p(I E n)=1-\prod_{i=}^{3}(1-q n i)
$$

Where:

$p(I E n)=$ probability of failure of intermediate event (process $n$ ).

qni = probability of basic event failure (BEi) causing the failure of the intermediate event IEn. The basic events could be failure of technician, failure of software or failure of calibration.

Equation (7) determines the probability of failure of the preventive layer $n$ :

$$
p(P \operatorname{Ln})=1-\prod_{i=}^{3}(1-q p n i)
$$

\section{Where:}

$p(P L n)=$ probability of failure of the protective layer $n$.

qpni = probability of basic event failure (BEi) causing the failure of protective layer PLn. The basic events could be failure of technician, failure of software or failure of calibration.

The probability of failure of process $n$ and the preventive layer $\mathrm{n}$ is determined by (8), which is the combination of (6) and (7).

$$
p(\text { IEn and } P L n)=\left[1-\prod_{i=}^{3}(1-q n i)\right]\left[1-\prod_{i=}^{3}(1-q p n i)\right]
$$

Equation (9) determines the probability of failure of processes 1 to $\mathrm{n}$ and preventive layers 1 to $\mathrm{n}$, which, assuming they do not intercept each other, is the sum of all equations.

$$
p(T E)=\left[1-\prod_{i=}^{3}(1-q \mid i)\right]\left[1-\prod_{i=}^{3}(1-q 1 p i)\right]+\ldots+\left[1-\prod_{i=}^{3}(1-q n i)\right]\left[1-\prod_{i=}^{3}(1-q p m i)\right]
$$

The event tree may have as many reactive layers, as required, as shown in Figure 6.

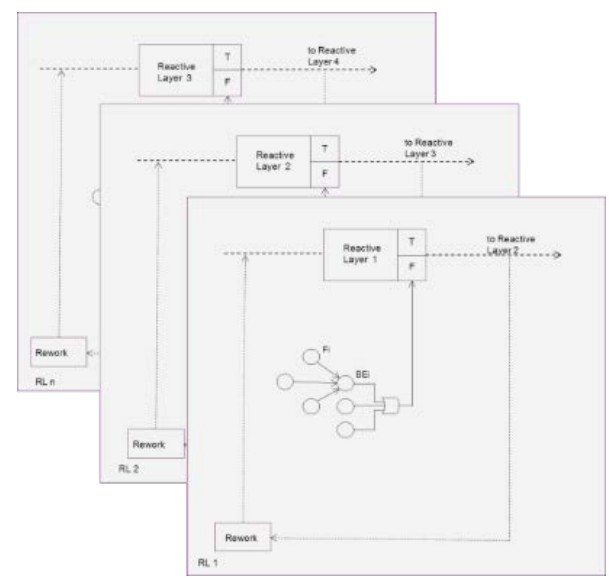

Fig.6. Reactive layers

Equation (10) determines the probability of failure of reactive layer 1 :

$$
p(R L 1)=1-\prod_{i=}^{3}(1-q 1 r i)
$$

Where:

$p(R L 1)=$ probability of failure of reactive layer 1

q1ri = probability of basic event failure (BEi) causing the failure of reactive layer 1 . The basic events could be failure of technician, failure of software or failure of calibration.

Equation (11) determines the probability of failure of the reactive layer $n$

$$
p(R L n)=1-\prod_{i=}^{3}(1-q r n i)
$$

Where:

$p(R L n)=$ probability of failure of reactive layer $n$

qrni = probability of basic event failure (BEi) causing the failure of reactive layer $n$. The basic events could be failure of technician, failure of software or failure of calibration.

The probability of failure of the reactive layers 1 to $n$ is determined by the combination of all equations. Equation (12) determines the probability of engine operational failure.

$$
p(\mathrm{OF})=\left[1-\prod_{i=}^{3}(1-q 1 r i)\right] \times \ldots \times\left[1-\prod_{i=}^{3}(1-q r n i)\right]
$$

The Fault Tree and Event Tree are joined by the Top event, as shown in Figure 7. 

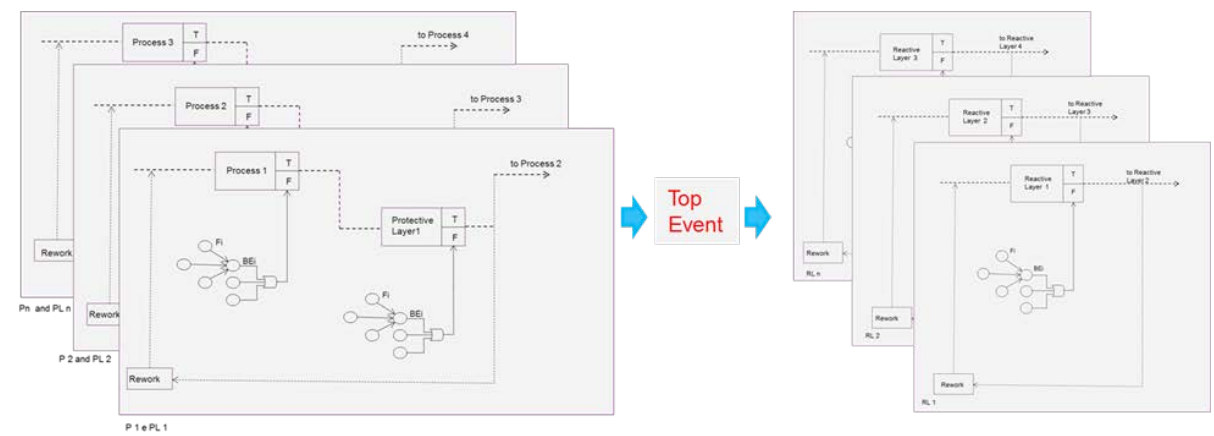

Fig.7. Combination of a fault tree and event tree

Equation 13 determines the probability of engine operational failure and combines all equations.

$$
\begin{aligned}
p(\mathrm{OF})=\left[1-\prod_{i=}^{3}(1-q 1 i)\right] & {\left[1-\prod_{i=}^{3}(1-q 1 p i)\right]+\ldots+\left[1-\prod_{i=}^{3}(1-q n i)\right]\left[1-\prod_{i=}^{3}(1-q p n i)\right] x } \\
& {\left[1-\prod_{i=}^{3}(1-q 1 r i)\right] \times \ldots \times\left[1-\prod_{i=}^{3}(1-q r n i)\right] }
\end{aligned}
$$

A causal model portrays progression of events over time, while BBN, Fault Trees and Event Trees represent the logic corresponding to failure of complex systems. The integrated structure of the model is represented by the framework of the Fault Tree connected via the top event TE to the base of an Event Tree. The latter branches out from the initiating critical event to potential consequences of engine failure in operation named operational failure "OF". Preventive barriers PL1, PL2 and PL3 in the Fault Tree and the reactive layers RL1, RL2 and RL3 in the Event Tree are part of the bow-tie diagram. The connecting lines from a Fault Tree basic fault to any Event Tree branch end consequence form a scenario, so one bow-tie can show many scenarios.

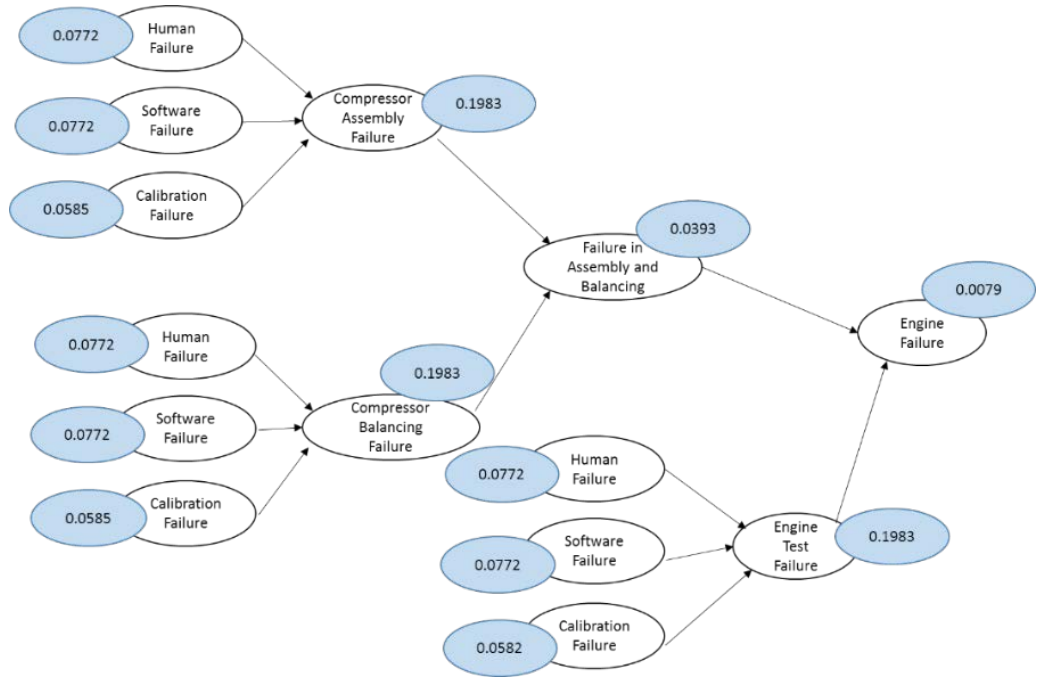

Fig.8. Bayesian network of compressor assembly process

Figure 8 shows an example of general Bayesian network obtained with the combination of specific Bayesian networks generated from the fault tree and event trees. The network represents the node "failure in compressor assembly", the node failure in compressor balancing" and the node "failure in engine testing". A Bayesian network software is used to run the model, the probability values obtained for the nodes are also shown in the Figure 8 . The aggregation of 
all probabilities results in a probability of engine failure of 0.0079 . This value was obtained assigning the probability of failure of 0.01 to all primary independent variables.

Figure 8 shows that the probability of engine failure is 0.0079 . A failure in testing contributes with a probability of 0.1983 , while a failure in compressor balancing has a probability of 0.0393 . In the test failure, the human failure contributes with 0.0772 , software failure with 0.0772 and calibration failure with 0.0582 . The failure of assembling and balancing the compressor contributes with 0.1983 . In the compressor assembly failure, the human failure contributes with 0.0772 , the software failure with 0.0772 and calibration failure with 0.0585 . The same happens to the failure of balancing. The final result is a probability of engine failure of 0.0079 .

\section{CONCLUSION}

This paper presents a model that combines Fault Tree analysis, Event Tree analysis and Bayesian Belief Networks in an integrated model that can be used by decision makers to identify critical risk factors in order to allocate resources to improve the safety of the system. The result of this study adds to the body of evidence that the methodology for probabilistic risk analysis and causal model in jet engine manufacturing industry is feasible and the model is a powerful tool to be used by decision makers in the jet engine manufacturing industry.

The methodology for building the structure of the model, which is a causal model for probabilistic risk assessment in the manufacturing of jet engines, has been presented and consists of a procedure for the construction of the Bayesian belief network fault tree, event tree and bow tie in a situational operation. The single homogeneous structure of the model allows consistent handling of probabilities of the factors affecting engine failure and their interdependence.

A partial validation of the model was presented for the compressor assembly, balancing an engine testing. The results need to be validated in more detail, in order to make sure the fault trees, event trees and Bayesian networks functions correctly in a real application. The application of the model to the process of jet engines manufacturing in a real situation needs to be performed successfully in order to validate the model. Independent data obtained from experts elicitation process need to be used to feed the model with numbers and verify the probability of engine failure. Result of calculations need to be discussed with the experts to identify discrepancies to be corrected. The causal model can be used as a tool to safety decisions in the industries of jet engines manufacturing.

\section{REFERENCES:}

Ale, B.J.M., Bellamy, L.J., Cooke R.M., Goossens, L.H.J., Hale, A.R., Roelen, A.L.C., Smith, E.,( 2006). Towards a causal model for air transport safety - Ongoing research project. Safety Science 44, 657-673.

Brooker, P., (2011). Experts, Bayesian Belief Networks, rare events and aviation risk estimates. Safety Science 49, 1142-1155.

Calixto, Eduardo, Lima, G.B.A, Firmino, Paulo Renato Alves, (2013). Comparing SLIM, SPAR-H and Bayesian Network Methodologies. Open Journal of Safety Science and Technology 3, 31-41.

Cepin M, He X., (2006). Development of a method for consideration of dependency between human failure events. In: Soares CG, Zio E, editors. Proceedings of ESREL2006: safety and reliability for managing risk, 285-91.

Cepin M., (2007). Importance of human contribution within the human reliability analysis (IJS-HRA). J Loss Prevent Process Industry.

Ding, S., Kamaruddin, S., Azid, I. A. (2014). Development of a model for optimal maintenance policy selection. European J. Industrial Engineering, 8 (1), 50-68.

Droguett EL, Groen F, Mosleh A., (2004). The combined use of data and expert estimates in population variability analysis. Reliability Engineering and System Safety 83, 31121.

Esteves, A. S.; Lima, G.B.A; Quelhas, O. L. G. (2005). Process Risk Assessment and Management in a Petroleum Production Nucleus. Petroleum Science and Technology; 23: 5-6.

Fu, Yan-Kai; Chan, Tsung-Lung., (2013). A conceptual evaluation framework for organizational safety culture: An empirical study of Taipei Songshan Airport. Journal of Air Transport Management.

Groth K, Swiler L P., (2013). Bridging the gap between HRA research and HRA practice: A Bayesian network version of SPAR-H. Reliability Engineering and System Safety 115, 33-42.

Janic, Milan, (2000). An assessment of risk and safety in civil aviation. Journal of Air Transport Management 6 (1), $43-50$.

Kamrani, A. K., Adat, A., Azimi, M. (2011). Methodology for analysis of manufacturing operations due to complexity. International Journal of Industrial Engineering, 18(2), 71-82.

Kumamoto H, Henley EJ., 2007. Probabilistic risk assessment and management for engineers and scientists. IEEE Press. 
Lahtinen J, Valkonen J, Bjorkman K., (2012). Model checking of safety-critical software in the nuclear engineering domain. Reliability Engineering and System Safety 105, 104113.

Lee, A, Wei, C., Lee, Y. (2010). An approach for modelling the risk transformation process. International Journal of Industrial Engineering 17, No 1.

Liou, James J.H.; Yen, Leon; Tzeng, Gwo-Hshiung, (2008). Building an effective safety management system for airlines. Journal of Air Transport Management 14, 20-26.

Mahadevan S., Zhang R. Smith N., (2001). Bayesian networks for system reliability reassessment. Structural Safety 23(3), 231-51.

Marais K B, Robichaud M.R. L., (2012). Analysis of trends in aviation maintenance risk: An empirical approach. Reliability Engineering and System Safety 106, 104-118.

Mosleh A., (1992). Bayesian modeling of expert-toexpert variability and dependence in estimating rare event frequencies. Reliability Engineering and System Safety 38 47-57.

Netjasov, Fedja; Janic, Milan., (2008). A review of research on risk and safety modelling in civil aviation. Journal of Air Transport Management 14, 213-220.

Nieuwenhuyse, I. V., Mahihenni, M.H., (2014). Trading off inventory, capacity and customer service in semi-process industries: a case study at SEPPIC. European J. Industrial Engineering, 8 (1), 90-110.

Nureg, (2001). Fault Tree Handbook 01492. Nuclear Regulatory Commission. Nureg.

Pasman, H. J.; Rogers, W., (2013). Bayesian networks make LOPA more effective, QRA more transparent and flexible, and thus safety more definable! Journal of Loss Prevention in the Process Industries; 26: 434-442.

Pereira, J.C, Lima, G.B.A., (2012a). Critical operational risk factors in the aeronautical maintenance industry. In: Brazilian Association of Production Engineering (ENEGEP), TN-STO-158-925-19430, Bento Gonçalves, Brazil. .

Pereira, J.C. (2014b), D. Sc. Thesis. Causal model for probabilistic riskanalysis of jet engine failure in manufacturing situational operation (CAPEMO). Universidade Federal Fluminense (UFF), Brazil.

Pereira, J.C., (2012c). Indicators of safety culture in the aeronautical maintenance industry, 163/2012. In: Symposium of Logistics, Production and International Operations (SIMPOI - FGV), São Paulo, Brazil.

Pereira, J.C., Lima, G.B.A, (2012d). Critical elements in the development of Safety Management System in the aeronautical maintenance industry. In: National Congress in Excellence in System Management (CNEG), Universidade Federal Fluminense, Niteroi, Brazil.

Pereira, J.C.; Lima, G.B.A., (2013e). Contribution on the safety analysis of jet engines production system. In: Risk Brazilian Association (ABRISCO), Rio de Janeiro, Brazil.

Pereira, J.C.; Lima, G.B.A., (2014f). Probabilistic Risk Analysis in Manufacturing Situational Operation. Phd Seminar. CIO-ICIEOM-IIIEC 2014. Malaga, Spain.

Pereira, J.C.; Lima, G.B.A; Santanna, Annibal P., Simões, Salvador; Pizzolato, Nelio, (2014g). Causal Model for Probabilistic Risk Analysis of Jet Engine Failure in Manufacturing Situational Operation (CAPEMO). International Journal of Engineering Science and Innovative Technology (IJESIT), 3 (3), Pages 701-717.

Petersen, D., (2000). Safety management our strengths \& weaknesses. Professional Safety 16-19.

Podofillini L, Dang V.N., (2013). A Bayesian approach to treat expert-elicited probabilities in human reliability analysis model construction. Reliability Engineering and System Safety 117, 52-64.

Rechenthin, D., (2004). Project safety as a sustainable competitive advantage. Journal of Safety Research 35, 297308.

Sutrisnowati, R A., Bae, H., Park, J., (2014). Bayesian Network Learning for port-logistics-process knowledge discovery. International Journal of Industrial Engineering 21, No 3.

Trbojevic, V. M, Carr, B. J., (2000). Risk based methodology for safety improvements in ports. Journal of Hazardous materials 71, 467-480.

Weber P, Medina-Oliva G, Simon C, Lung B., (2012). Overview on Bayesian networks applications for dependability, risk analysis and maintenance areas. Engineering Applications of Artificial Intelligence 25(4), 67182.

Zuijderduijn, C. (2000). Risk Management by Shell Refinery Chemicals at Pernis, The Netherlands. EU Joint Research Centre Conference on Seveso II Safety Cases. Athens. 